\title{
Effects of Origami Pattern Crash Box and Rectangular Pattern Crash Box on The Modelling Of MPV Car Structure on Deformation
}

\author{
Imam Kusyairia, Helmy Mukti Himawann, Moch Agus Choiron ${ }^{c}$ Yudy Surya Irawan ${ }^{\mathrm{d}}$ \\ a,b Politeknik Kota Malang \\ JI Raya Tlogowaru No 3, Malang, Indonesia \\ Telephone/fax 0341-754088. \\ e-mail: kusyairi@poltekom.ac.id \\ c,d Brawijaya University \\ Mechanical Engineering Department
}

\begin{abstract}
Crash box serves as a kinetic energy absorber during collision. It has a tube shape, which is located between bumper and chassis. The crash box design requires development in order to reduce buckling mode and obtain symmetry folding mechanism, so it will achieve greater energy absorption. The researchers find a method to reduce tension due to impact by providing dents in crash box geometry. This research observed origami pattern crash box design having dents functioned as pre-folded so that collapse mode can be predicted and stable. In this research, the crash box was modeled according to the size of bumper and chassis on the MPV car. Testing simulation was performed by modelling Impactor as rigid body and crash box as flexible. Fixed support was housted in the surface of rear side of the crash box. Simulation process was started from the impactor moving to suppress crash box. This Impactor collision led to deformation on the crash box. Crash box material was AA7004-T7, it was modelled as bilinear isotropic hardening. Based on the research result, the addition of pre folded pattern is able to reduce impact force at the first impact and has stable characteristic as well as predictable collapse mode.
\end{abstract}

Keywords: crash box; origami; segment; pre folded

\section{INTRODUCTION}

Accident is the third largest cause of death in the world. It is a challenged case for many parties to reduce the number of deaths due to accidents. One of the parties is from the automotive field; they try to reduce the risk of death caused by accidents by equipping the car with several safety tools, one of which is the installation of crash box in car structure. Crash box serves as a kinetic absorber during collision, then when the accident happen, the front part of this tool will experience deformation. The shape of crash box is usually tube or beam. It is located between bumper and chassis and the function is shown in Figure 1.

An analysis by Ohokubu et al, Johnson et al, Wierzbicki and Akerstrom, Alexander et al was performed by expressing it in terms of geometry and material properties. Wierzbicki and Abramowicz combine an approach using kinematics plasticity. Mean crushing load can be expressed with

$$
P_{m}=38,27 M_{o} C^{1 / 3} t^{-1 / 3}
$$

Where $P_{m}$ is the mean axial crushing force, $M_{0}=\sigma_{0} t^{2} / 4, \sigma_{0}$, is the mean voltage current, $\left(\sigma_{0}=(0,9\right.$ to 0,95$\left.) \sigma_{u}\right)$. $\sigma_{u}$ is ultimate tensile strength from the material, $C=1 / 2$ 
$(b+d)$ with $b$ and $d$ become column side of a rectangular box, and $t$ is the wall thickness. For square tube, where $C=d=b$, the equation of 2.1 is simplified into:

$$
P_{m}=9,56 \sigma_{0} t^{5 / 3} b^{1 / 3}
$$

Research on crash box has been done a lot such as aluminum foam crash box with box tube model [2], tubular crash box [3,4] and multilevel tubular crash box [5,6]. The crash-box development pattern is developed with two considerations: (1) the absorption of kinetic energy and power to maintain the structure due to accidents. (2) The ability to withstand load of axial collapse and bending. The level of folds or collapse regularity will depend on the thickness and rigidity ratio of geometric, i.e. curvature. The larger the curvature (greater geometric rigidity), the more regular the collapse pattern is [7]. To achieve these two things, the researcher developed several models of crash boxes by adding dents or indentations to crash box geometry $[8,9,10]$. These dents serve to form predictable deformation patterns. By adding dents to the surface of the crash box then the force/tension due to impact (initial buckling) can be reduced. Crash boxes should be stable, light, inexpensive, have recurrent deformation and easy mode in the manufacturing process. Development of crash box designs on geometry is required to reduce buckling mode and obtain symmetry collapse mode (folding mechanism), so the energy absorption is greater. In the development of geometry design, this research observed the theme of origami-pattern crash box having dents served as pre-folded so that collapse mode can be predicted and stable. Provision of dents is done by changing geometry of the crash box by adding one or some indentation point(s) on the geometry. The research is then continued to find the effects of these dents.

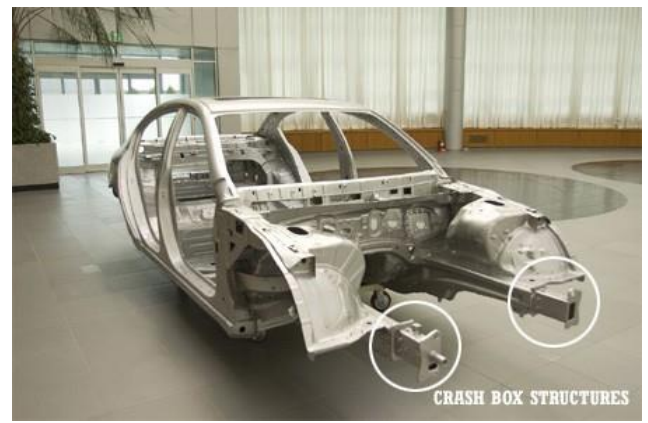

Figure 1. Crash Box Allocation

The research is developed into pre-folded patterns on origami that has been studied by Ma $\mathrm{J}$ and You Z [7]. They examine the origami pattern crash box with low speed and find that pre folded pattern is able to produce predictable collapse and lead to the increase in energy absorption that reached $92.1 \%$. The next research is performed by Kusyairi, et al [11], they design the origami pattern crash box with the Taguchi method on high speed impact test, it is concluded that the origami pattern crash box is able to produce predictable collapse mode and the greatest absorption was geometry that has many and thick segments. Origami pattern crash box collision research on the direction of corner collision has also been performed by Bintarto et al [12] and Zhou et al [13], it is found that pre folded mode of origami pattern capable of producing predictable collapse mode.
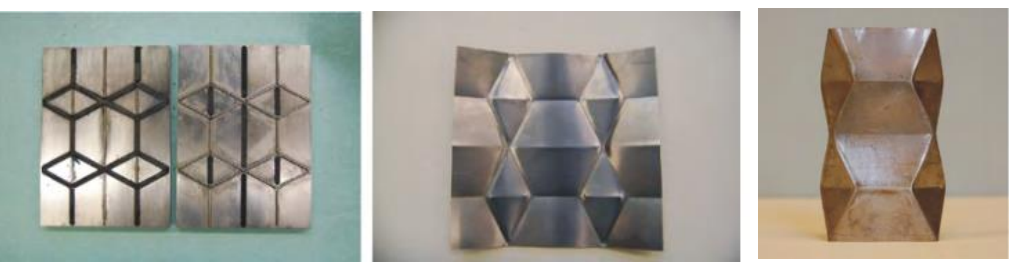

Figure 2. Construction of Origami Pattern Crash Box by stamping method [7] 
The development of origami pattern crash box on the addition of origami trapezoid geometry model is performed by Zhou et al [14] the development of origami pattern with reconfigurable polygonal cross-sections model is performed by Filipov et al [15] and the development of origami pattern on Axial crushing is performed by Song et al [16]. In addition to research with finite element software, research is also performed on manufacturing methods, this is done by Ma, Jiayao [17] by Stamping method, this can be seen in Figure 1, and also done by Li, Siqi et al [18], indicating that origami pattern crash box can be done using manufacturing method.

In previous study, the origami pattern crash box was modeled as square, however, it must be difficult if it is applied to MPV cars in Indonesia because dimensions of bumper and chassis are different. Therefore, in this research, the origami pattern crash box was modelled as rectangular with sizes that is adjusted to the MPV car. The objective of this research is to find the energy absorbed and deformation patterns of crash box when geometry is adjusted to the MPV car.

\section{Method}

\subsection{Modelling}

Crash box was modelled according to the size of bumper and chassis on MPV car. This is different from previous research, if in previous research crash box was modeled as square, then in this research, the crash box was modelled as rectangle adjusted to real condition of MPV car, as seen in figure 3 and 4 , with $2 \mathrm{~mm}$ thick crash box. The origami pattern crash box modeling was performed by taking optimum geometry data from previous research [11,12], which were number 3,5 and 7 with segments of 6,3 and 5 respectively.

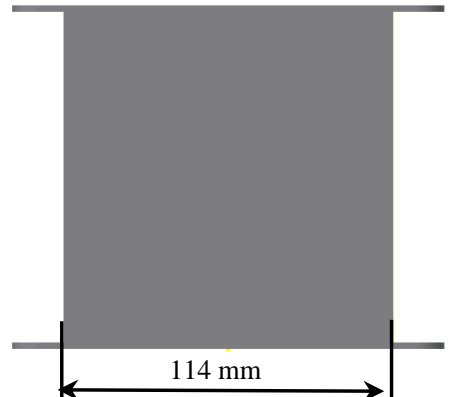

Front view

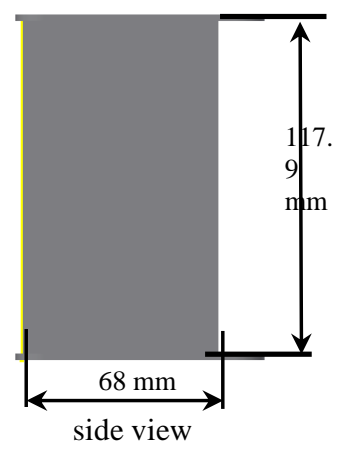

Figure 3. Crash box dimension

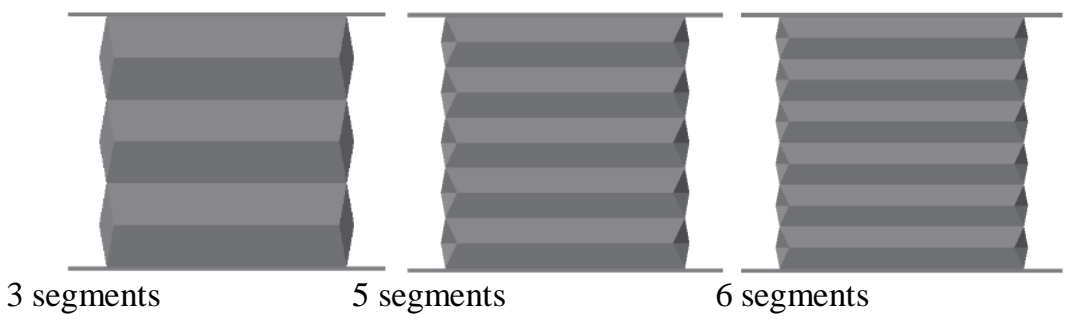

Figure 4. Origami pattern crash box

The result of crash box modelling design was seen in Figure 3 and 4, both of them had the same dimensions of length, width and height. The different was only on the prefolded pattern in origami-pattern crash-box. The crash box was already adjusted to bumper and chassis geometry on MPV cars. In order to adjust the length and width to the real conditions, so the origami-pattern crash-box design with top view was found as seen in figure 5 . 


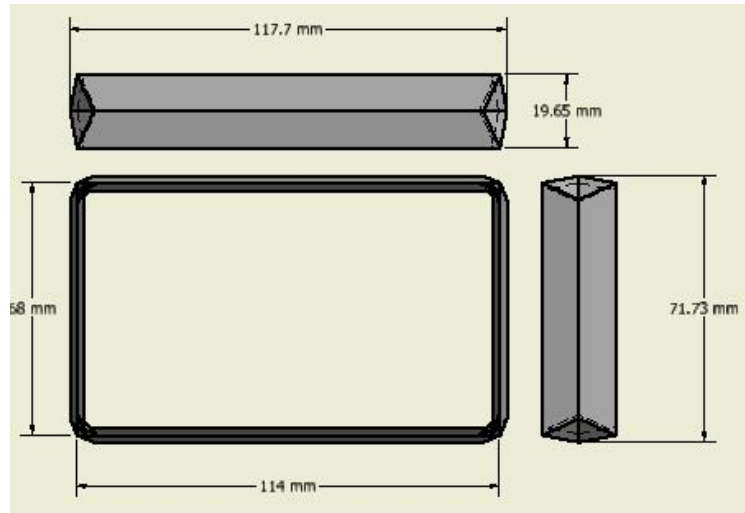

Figure 5. top view and the size of 6-segments origami pattern

\subsection{Testing Modelling}

After designing crash box modelling, then the result design was run in finite element software. Figure 6 shows the meshing process in the crash box. Messing process was one of the important stages in FEM simulation. In such process, the volume of an object was divided in order to be analyzed into parts or small area. This meant, if the meshing process was performed in smaller (smoother) area then the FEM simulation results would be more accurate, and this also required greater computation time and power. In the process of simulation testing, impactor was modeled as rigid body and crash box as flexible. Meanwhile, fixed support was located on the back surface of the crash box. The gravitational force was shown in figure 6 of $y$-axis direction. Speed impactor pressed the crash box by $\mathrm{Y}$-axis direction. The simulation process was begun when the impactor moved on the $y$-axis direction and pressed the the crash box, the impactor moved at a speed of $16 \mathrm{~km} / \mathrm{h}$. Impactor pressure resulted in crash box deformation. The simulation process can be seen in Figure 6.

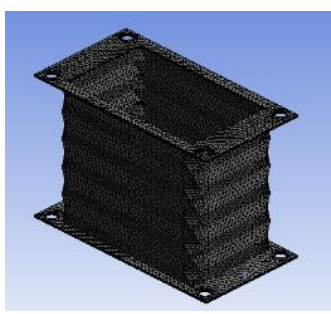

a. Meshing

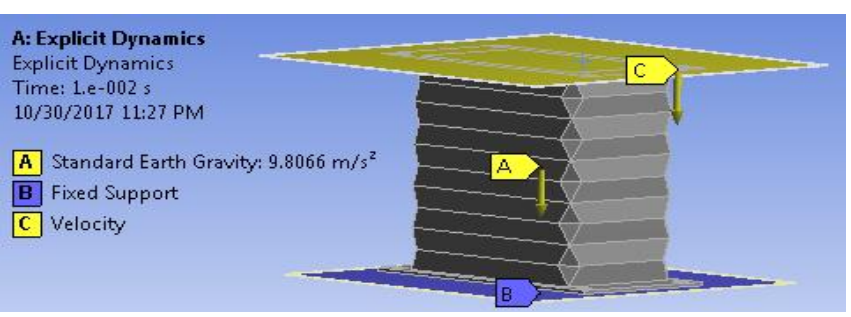

b. testing model

Figure 6. Meshing and testing model

\subsection{Material Modelling}

In this research, the material was modeled as bilinear isotropic hardening. This meant when the impact occurred, the material experienced elastic deformation followed by plastic deformation. When the material experienced additional loaded, then the deformation of such material increased. This plasticity material model is often used in strain analysis. Bilinear isotropic hardening modeling was made by inputting yield strength and modulus tangent data in the Finite Element Software. The material used was AA7003-T7 with mechanical properties of Young Modulus by 71 (GPa), Yield Strength by $247(\mathrm{MPa})$ and Tangent Modulus by $0.5(\mathrm{GPa})$. 


\section{Result ANd Discussion}

It is the same with initial hypothesis that pre-folded pattern given to dents can activate symmetrical collapse mode (folding mechanism), reduce buckling mode, as well as produce predictable and stable collapse modes. In figure 7 , if it is seen from the front view, all crash boxes look as if to have symmetry collapse mode, but the differences can be seen clearly in figures 8 and 9 . In figure, 9 if it is seen from the side view, rectangular crash box has already experienced buckling at $0.002 \mathrm{~s}$, the origami pattern crash box still shows the symmetry pattern and still able to maintain the folding mechanism, only at 0.01 s, 3-segment origami pattern crash box experience segment shift in its middle part, but this does not happen in the 5-and-6-segments origami pattern that are still symmetry.

This is also supported by figure 8 showing from the corner views in which buckling is seen to be happened in rectangular pattern crash box, yet in the origami pattern crash box, the impact force is distributed to its pre-folded pattern, consequently, one of the sides is concave, while the other side is convex. In Figure 9 of 3 -segments origami pattern crash box, impact energy suppresses crash box outward at $0.002 \mathrm{~s}, 0.045 \mathrm{~s}$ and $0.007 \mathrm{~s}$, but at $0.01 \mathrm{~s}$, pre folded pattern unable to withstand the impact load, this is different from the 5-and-6-segments origami pattern crash box in which symmetric collapse modes can be formed when there are more segments.

In Figure 8, form the corner view, the middle part of segment in the 3-segments origami pattern crash box experiences first deformation at $0.02 \mathrm{~s}$ with convex reaction, when it is already reached $0.01 \mathrm{~s}$, the middle part of segment is unable to hold the impact energy and lead to buckling. In the 5 segment crash box, the deformation also starts from the middle part, the long section of the geometry forms a concave while width section of the geometry forms a convex. This also happens in the 6-segments crash box, where the initial indentation occurs in the middle part of segment and then it is followed by the formation of indentation and convex respectively in its length and width section of the geometry. It is because every corner of the origami pattern crash box is designed to be opened when it is exposed by impact force that lead to the concentration of impact energy centered in each segment, if one segment is not able to withstand the impact then it will proceed to another segment, that is why origami pattern crash box as seen in figure 8 still has survived segment area even though another segment has already experienced deformation. In 5-segment crash box, deformation is also started from the middle part of the geometry and then it moves to the upper part, this also happens in 6-segment crash box.
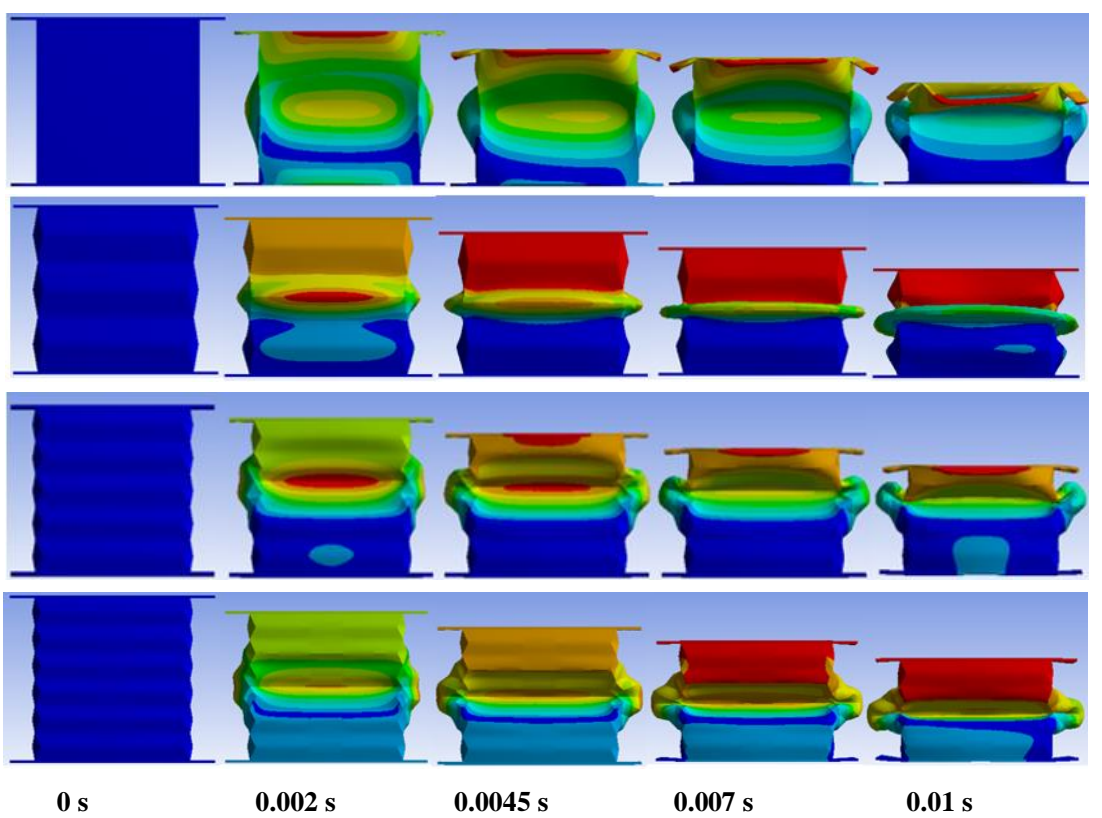

Figure 7. Crash box deformation pattern 
However, it is different form the rectangular pattern crash box that does not have any corners and segments, so that the impact energy is distributed to all crash box geometry and lead to buckling. Addition of pre folded also serves to reduce collision force the initial impact and has stable characteristic. Based on the visual observation above, it is concluded that number of segment affect deformation ability on origami pattern crash box. Consequently, the more number of segment is, the more crash box can absorb it maximally.

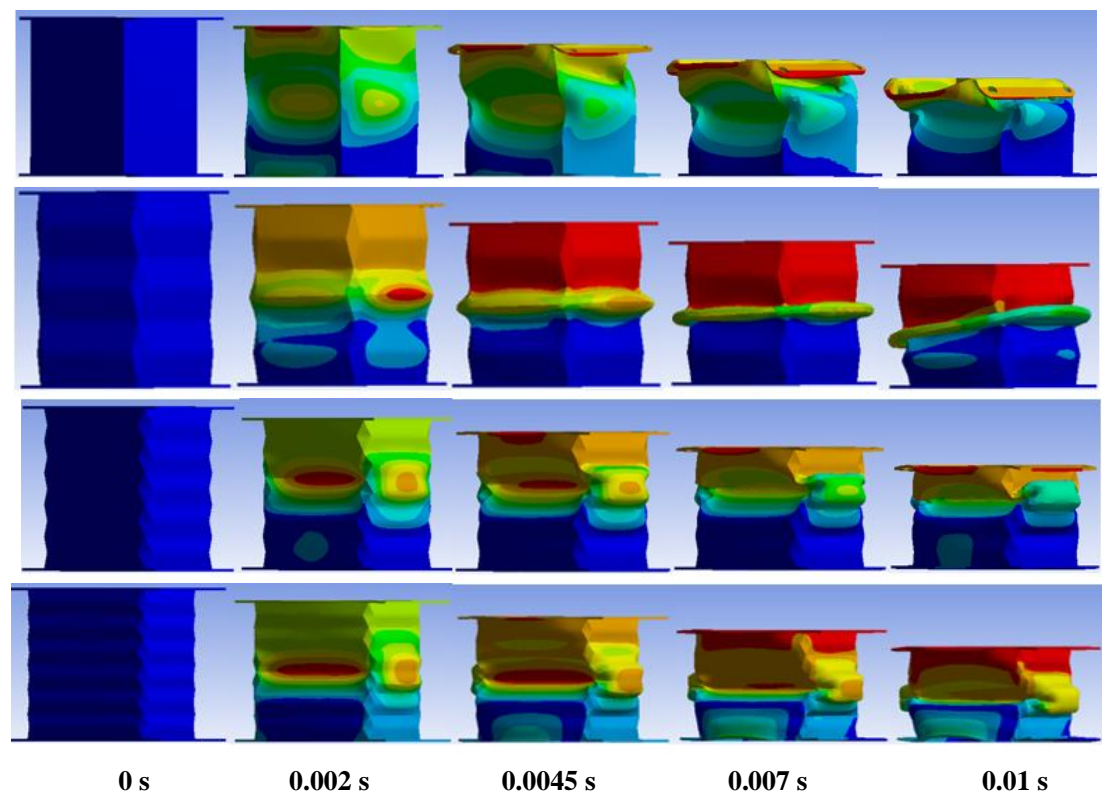

Figure 8. Crash box deformation pattern
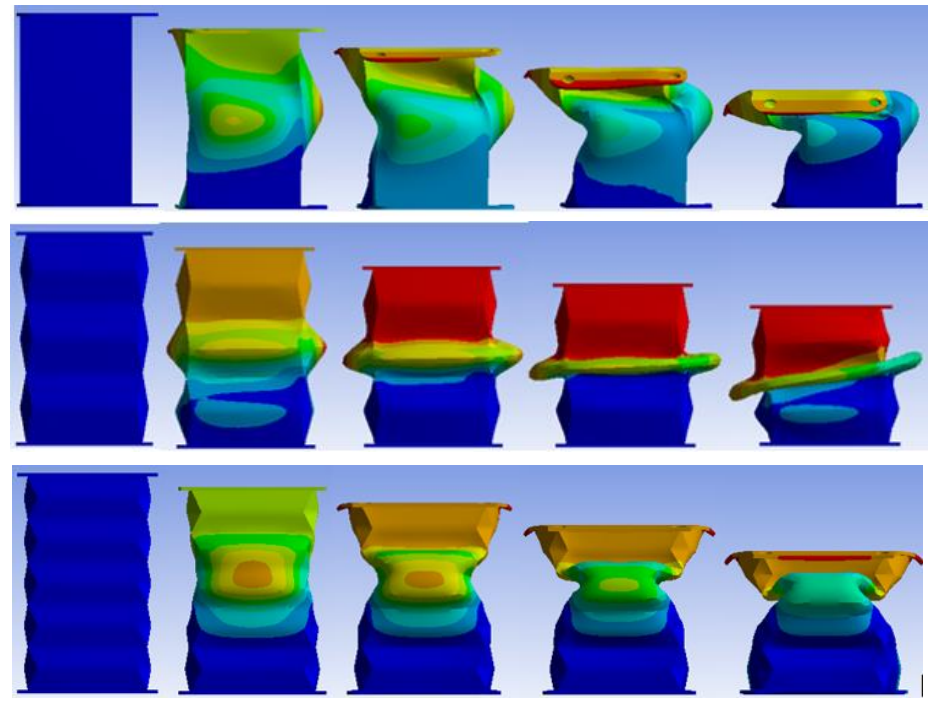

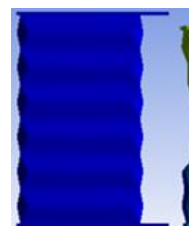

$\mathbf{0} \mathbf{s}$

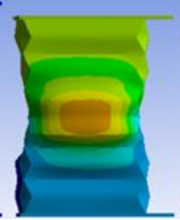

$0.002 \mathrm{~s}$

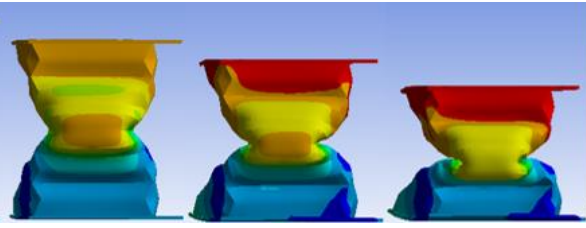

$0.0045 \mathrm{~s}$

$0.007 \mathrm{~s}$

0.01 s

Figure 9. Crash box deformation pattern 


\section{CONCLUSION}

1. Pre folded pattern in origami pattern crash box can absorb kinetic energy.

2. Pre folded pattern in origami pattern crash box can trigger predictable collapse pattern.

3. Further research requires research on bumper and chassis structure.

4. Further research requires research on simulation and experimental equation, and manufacturing process.

\section{ACKNOWLEDGMENT}

The Ministry of Research, Technology and Higher Education, the Directorate General of Strengthening Research and Development, and the Directorate of Research and Community Service that has financed the entire research, Announcement 0045/E3/LL/2018 dated January 16, 2018

\section{REFERENCES}

[1] Bois, Paul Du, Clifford C. Chou, Bahig B. Fileta, Tawfik B. Khalil, Albert I. King, Hikmat F. Mahmood, Harold J. Mertz dan Jac Wismans , Vehicle Crashworthiness And Occupant Protection. Michigan American Iron and Steel Institute 2000 Town Center Southfield, Michigan 48075 (2004).

[2] Min, B.S. \& Cho, Jaeung, Impact Characteristic According to the Structure of Crash Box at the Vehicle. Archives of Metallurgy and Materials. 62. . 10.1515/amm-20170151 (2017).

[3] Nasir Hussain, N \& Prakash Regalla, Srinivasa \& V Daseswara Rao, Yendluri, Comparative Study of Trigger Configuration for Enhancement of Crashworthiness of Automobile Crash Box Subjected to Axial Impact Loading. Procedia Engineering. 173. 1390-1398. 10.1016/j.proeng.2016.12.198 (2017).

[4] Marzbanrad, Javad \& Keshavarzi, Ahmad \& Haji Aboutalebi, Farhad, Influence of elastic and plastic support on the energy absorption of the extruded aluminium tube using ductile failure criterion. International Journal of Crashworthiness. 19. 172-181. 10.1080/13588265.2014.883678 (2014).

[5] Altin, Murat \& Halis, Serdar \& Serdar Yücesu, H, Investigation Of The Effect Of Corrugated Structure On Crashing Performance In Thin-Walled Circular Tubes. International Journal of Automotive Science and Technology. 1. 1-7 (2017).

[6] Choiron, Moch \& B. Darmadi, Djarot \& Rahmaddian Anwari, Bintang, Analisis Penyerapan Energi Dan Pola Deformasi Crash Box Dengan Variasi Sudut Tirus Dinding Crash Box Pada Uji Simulasi Tabrakan Arah Frontal. Jurnal Rekayasa Mesin. 6. 75-83. 10.21776/ub.jrm.2015.006.01.11 (2015).

[7] Ma, Jiayao, Energy Absorption of Thin-Walled Square Tubes With a Prefolded Origami Pattern-Part I: Geometry and Numerical Simulation. Journal of Applied Mechanics. 81. 1003-. 10.1115/1.4024405 (2013).

[8] Ghasemnejad, Hessam \& Hadavinia, Homayoun \& Marchant, D \& Aboutorabi, A, Energy absorption of thin-walled corrugated crash box in axial crushing. SDHM Structural Durability and Health Monitoring. 4 (2008).

[9] Chiu, Yuen-Sheng \& Jenq, Syh-Tsang, Crushing behavior of metallic thin-wall tubes with triggering mechanisms due to quasi-static axial compression. Journal of the Chinese Institute of Engineers. 37. . 10.1080/02533839.2013.800275 (2014).

[10] Karagöz, Selçuk \& Yildiz, Ali, A comparison of recent metaheuristic algorithms for crashworthiness optimisation of vehicle thin-walled tubes considering sheet metal forming effects. International Journal of Vehicle Design. 73. 179-188. 10.1504/IJVD.2017.10003410 (2017).

[11] Kusyairi, Imam, Moch. Agus Choiron dan Anindito Purnowidodo, Pengaruh Variasi Desain Crash Box Pola Origami terhadap Kemampuan Penyerapan Energi. Jurnal Rotor Universitas Negeri Jember. Vol 8 NO 2 (2015). 
[12] Bintarto, Redi, Andik Atmaja dan Imam Kusyairi, Analisis Penyerapan Energi Crash Box Pola Origami pada Pengujian Frontal Impact Posisi Angular Frontal. Jurnal Rekayasa Mesin Universitas Brawijaya. Vol 8, No 1 (2016).

[13] Zhou, Caihua \& Jiang, Liangliang \& Tian, Kuo \& Bi, Xiangjun \& Wang, Bo, Origami Crash Boxes Subjected to Dynamic Oblique Loading. Journal of Applied Mechanics. 84. . 10.1115/1.4037160 (2017).

[14] Zhou, Caihua \& Zhou, Yan \& Wang, Bo, Crashworthiness design for trapezoid origami crash boxes. Thin-Walled Structures. 117. 257-267. 10.1016/j.tws.2017.03.022 (2017).

[15] Filipov,E.T.,G.H. Paulino and T. Tachi. (2015). Origami tubes with reconfigurable polygonal cross-sections Proc. R.Soc.A472: 20150607.

[16] Song, Jie, Yan Chen, Guoxing Lu, Axial crushing of thin-walled structures with origami patterns. Elsevier. Thin-Walled Structures 54 (2012) 65-71 (2012).

[17] Ma, Jiayao, Thin-walled Tubes with Pre-folded Origami Patterns as Energy Absorption Devices. A dissertation submitted for the degree of Doctor of Philosophy in the Department of Engineering Science at the University of Oxford (2011).

[18] Li, Siqi, Sicong Ma, Chengqi Li, Xin Li, Origami Pattern Tube for Vehicle Crash Box, Department of Mechanical Engineering, Blekinge Institute of Technology,Karlskrona, Sweden. Bachelor of Science Thesis in Mechanical Engineering (2013). 